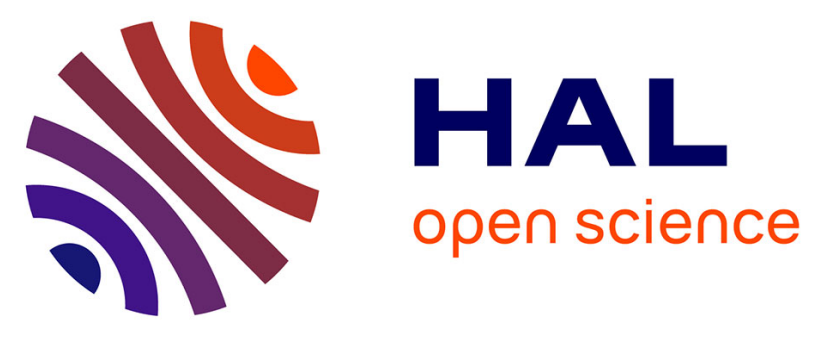

\title{
Systematization of Performance Evaluation Process for Industrial Productive Systems Considering Sustainability Indicators
}

Edson H. Watanabe, Robson Da Silva, Fabrício Junqueira, Diolino J. Santos Filho, Paulo E. Miyagi

\section{To cite this version:}

Edson H. Watanabe, Robson Da Silva, Fabrício Junqueira, Diolino J. Santos Filho, Paulo E. Miyagi. Systematization of Performance Evaluation Process for Industrial Productive Systems Considering Sustainability Indicators. 7th Doctoral Conference on Computing, Electrical and Industrial Systems (DoCEIS), Apr 2016, Costa de Caparica, Portugal. pp.77-85, 10.1007/978-3-319-31165-4_8 . hal01438306

\section{HAL Id: hal-01438306 https://hal.inria.fr/hal-01438306}

Submitted on 17 Jan 2017

HAL is a multi-disciplinary open access archive for the deposit and dissemination of scientific research documents, whether they are published or not. The documents may come from teaching and research institutions in France or abroad, or from public or private research centers.
L'archive ouverte pluridisciplinaire HAL, est destinée au dépôt et à la diffusion de documents scientifiques de niveau recherche, publiés ou non, émanant des établissements d'enseignement et de recherche français ou étrangers, des laboratoires publics ou privés.

\section{(c)(1)}

Distributed under a Creative Commons Attribution| 4.0 International License 


\title{
Systematization of Performance Evaluation Process for Industrial Productive Systems Considering Sustainability Indicators
}

\author{
Edson H. Watanabe ${ }^{1}$, Robson M. da Silva ${ }^{2}$. Fabrício Junqueira ${ }^{1}$, Diolino J. Santos \\ Filho $^{1}$ and Paulo E. Miyagi ${ }^{1}$ \\ ${ }^{1}$ University of São Paulo, São Paulo, Brasil, ${ }^{2}$ State University of Santa Cruz \\ Ilhéus, BA, Brazil \\ \{edsonh.watanabe, fabri, diolinos, pemiyagi\}@usp.br, \\ rmsilva@uesc.br
}

\begin{abstract}
Available industrial standards do not explicitly consider how to treat sustainability indicators in PS design and its control system. Therefore, this paper proposes a framework to systematize the performance evaluation process for industrial PS considering indicators that qualify and quantify its sustainability. The framework adopts Petri net technique and extensions of the standard ANSI/ISA95. Simulationbased analysis, decision making techniques and a PS's classification based on product green seal are also considered. Furthermore, the framework considers the processing information, storing and accessing each component using a Cyber Physical Technology due to the trend of PSs to be, in fact, a network for companies that are, in general geographically dispersed.
\end{abstract}

Keywords: productive system, Petri net, sustainability indicator

\section{Introduction}

Over the years, industrial productive systems (PSs) have been modified to include innovation [1], such as serialization, standardization and reconfiguration capabilities, however, without worrying about the waste of natural resources. Since the mid-80s, due to the scarcity of raw materials, non-governmental organizations, such as Roman Club, have been warned about the need to include sustainability in the PS design [13]. Thereby the governmental initiatives arose through the United Nations such as World Commission on Environment and Development [4], and events as Rio 92, Kyoto 97 and more recently Doha 2015. Currently, the PSs performance must be concerned to sustainability indicators, such as: reduction of negative impacts in conservation of energy and natural resources, management practices for safety assurance of the employees, communities, consumers and best practices for business feasibility and profitability). However, available industrial standards like ANSI/ISA95 do not explicitly consider how to treat sustainability indicators into the PS design and its control system [5]. Therefore, this paper proposes a framework to systemize the PS sustainability performance evaluation. Productive systems (PSs) concept used in this work is all industrial automated process, developed to execute activities to produce specific product, defined by stages such as: material preparation, assembly, validation test, and expedition. The framework considers enhancement of PS design requirements related to sustainability, adoption of Production Flow Schema 
(PFS) and Petri Net (PN) modeling techniques, extensions in the ANSI/ISA95 standard in order to include sustainability indicators. To evaluate the sustainability of PSs, a set of indicators must be measured to quantify and qualify the PS performance related to them. In turn, these indicators also must be used to guarantee certain grade of sustainability for PSs, positive impact on the environment, satisfaction of the employees, proper use of technology and profitable manufactured products. Thereby the framework also supports product classification based on sustainability seal. The performance and sustainability evaluation is based on computational environment of Cyber Physical Systems (CPS), which can be explored in PSs to create an infrastructure for data processing and acquisition, connecting elements to monitor variables that compose the sustainability indicators. According to a cloud computing vision, PS must explore CPS to assure a collaborative environment to (re)configure online productive processes that are executed in disperse PSs independently of its geographical localization.

The text is structured in sections: section 2 describes the importance of CPS to monitor sustainability indicators. Section 3 presents the considerations about industrial standard ANSI/ISA95, sustainability indicators and green seal. Section 4 shows the framework considered for the systematization of the performance evaluation process. Section 5 describes an example of the simulation and the analysis procedure. Section 6 reports the conclusions and further works.

\section{Cyber Physical System and Sustainability}

The deployment of cyber-physical systems (CPS) in for PSs is fundamental to use resources efficiently providing time economy, waste and cost reduction. PSs must be designed according to sustainable and service-oriented business practices, optimizing production processes to attend customer demand considering product features, deadline, costs, security, reliability, logistic and sustainability, also to achieve resource efficient production.

Then, CPS must be explored to create an smart infrastructure for data processing and acquisition, connecting elements to monitor variables that will compose the sustainability indicators. According to a cloud computing vision, PS must explore CPS to assure a collaborative environment to (re)configure online productive processes that are executed in disperse structure, independently of its geographical localization. These systems form the basis of emerging and future intelligent services, and improve the quality of life in many areas [6-8], providing the foundation of this proposal, including its infrastructure.

\section{Standards and Indicators}

Available industrial standards do not explicitly consider how to treat sustainability indicators in PS design and its control system. Therefore, a new approach must be considered, i.e., in this paper the ANSI/ISA95 standard is reviewed to meet the sustainability requirements. 
According to organizational structure of an industrial company established in ANSI/ISA95 [5], the production information is processed at level 3 - Manufacturing Execution System (MES). The results from the production performance analysis executed at MES are sent to the business level (upper level) that assists managers to make decisions (Figure 1, on the left side). The proposed review of this work is: the level 3 is re-interpreted to include a Sustainability Management System (SMS) module to treat sustainability, which is responsible for processing the data collected from the lower levels to calculate the sustainability indicators through information from PS infrastructure. In case of any indicators discrepancy, the SMS acts close to the existing MES modules in order to indicate and notify the higher level and to send commands for lower levels in accordance to directive established by the business level.

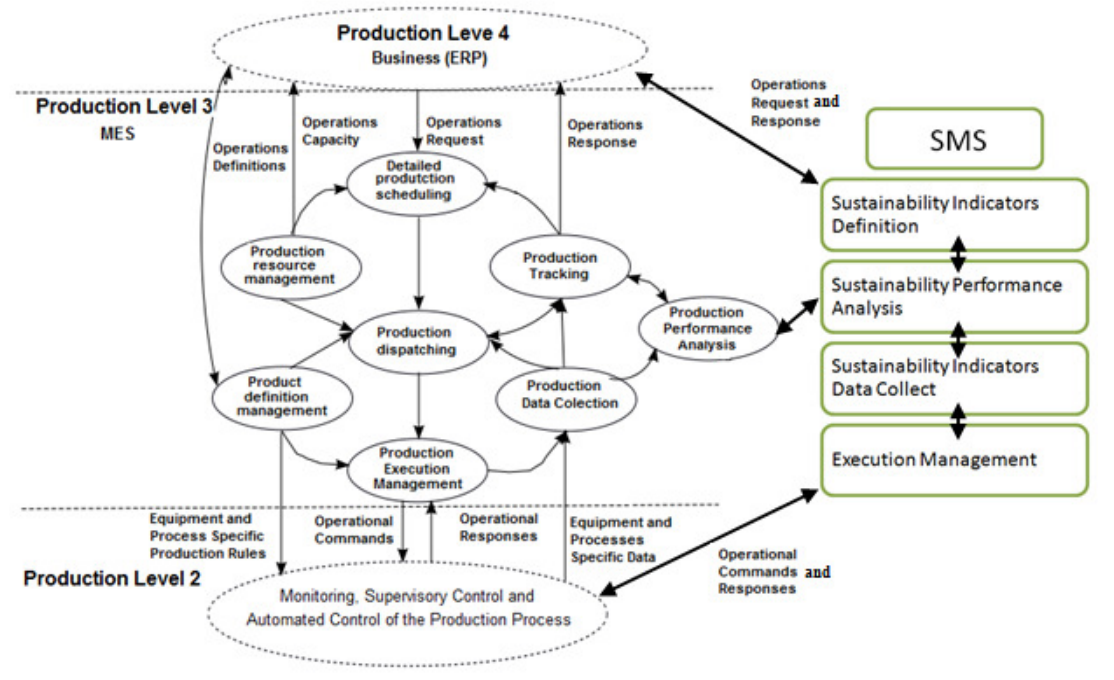

Fig.1. ANSI/ISA-95 norm and the proposed SMS module.

The SMS is composed by sub-modules:

- " sustainability indicators data collection", that stores the PS indicators data;

- "sustainability performance analysis", that calculates the performance of the PS based on data received from both the MES and PS sustainability indicators;

- "sustainability indicators definition", that deliveries the interface of a performance and a evaluation of sustainability indicators from other PSs that composes the disperse system to ensure compatibility among them;

- "execution management", that coordinates interactions among the SMS submodules and equipment located on inferior levels.

\subsection{Metrics and Indicators}

According to [9], sustainability indicators have three main objectives: enhance 
awareness and understanding, inform decision-making, and measure progress toward established goals. These indicators are qualitative or quantitative values used to evaluate the sustainability aspects of a system [10]. However, according to [11], the measure of the sustainability is more than just a set of indicators and there are different approaches to be considered, such as the definition of the actions set, in which the indicators must be verified. For e.g., [12] states that the result of this measurement should support the identification of specific areas to apply enhancements related to sustainability in PS activities. Analyzing the data achieved and its interpretation is other fundamental phase, since the difficulties are due to the complexity related to definition of several indicators $[13,14]$. Inter-relationships may bring the conclusions about the level of sustainability and decisions of future improvements.

Based on [15] and other references, due to limited space in this work, table 1 lists an indicator which can be used to a PS considering sustainability in four dimensions: environmental, economical, social and technological. For example: through the table is possible to determine the "Energy intensity index" by dividing energy consumed and unit of product ( $\mathrm{kWh} / \mathrm{unit})$. Thus, for each indicator chosen it is necessary to determine the index based on demand of the production.

Table 1: Example of Sustainability indicators (adapted from [12])

\begin{tabular}{|c|c|c|c|}
\hline Dimension & Sub-category & Indicator & $\begin{array}{c}\text { Quantification Method } \\
\text { (Yearly) }\end{array}$ \\
\hline Environmental & $\begin{array}{c}\text { Resource } \\
\text { Consumption }\end{array}$ & Energy intensity (kWh/unit) & Energy consumed/unit of product \\
& & \\
\hline
\end{tabular}

According to [16], the grade of sustainability may be used as a metric to evaluate the performance of PS. There are a pattern set of processes performance indicators, called Key Performance Indicator (KPI), which are measured to quantify and to qualify process performance evaluation. In the ISO standards [17, 18], the performance measure is treated as part of an industrial process creation value.

\subsection{Green Seal}

Based on similar initiative to encourage industries to produce in accordance to sustainability factors, such as economical, social, environmental and technological, it is also suggested a "green seal". This seal is also a register that the framework is in working order. All customers that buy products with green seal have the guarantee that they are helping to keep a better world. This way, the industry can show that it is doing something for the welfare of people and nature, and it also produces an extra motivation for its employees and local community. 


\section{Framework}

Based on previous works $[19,20]$, there is necessity to systematize the performance evaluation process for industrial PS, and a way do this, is through of a framework. Thus, the framework defines a procedure to evaluate the performance of PS considering indicators that qualify and quantify sustainability in PSs.

PSs can be approached as a Discrete Event System (DES) [21, 22] and based on this, Petri Net (PN) technique [23] can be adopted as a tool to systematize the modeling procedure, analysis and control specification (Figure 3). In fact, there are other techniques to model DES, but when the implementation of control solutions in industrial process is relevant; the models based on PN are considered the most effective an easy way to program industrial controllers [24]. Even though, the introduction of the sustainability concept does not change the nature of PS, its consideration at the system design stage is not trivial. Therefore, it is presented in Figure 2 the framework for the performance evaluation of sustainable PS [19, 20]. This Figure also shows a simplified flow of information.

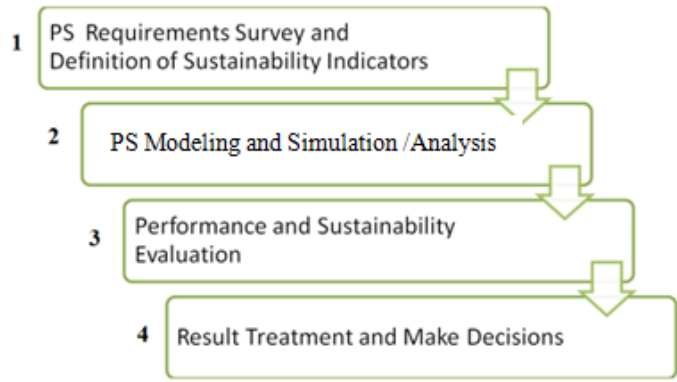

Fig.2. Framework for the analysis procedure of performance in sustainable PSs.

The proposed framework to perform evaluation of sustainable and dispersed PSs considers:

1. Specifications of physical machine operations and the types of technologies involved in the processes. Based on these specifications, data are extracted. The environmental resources data, materials and processes that composes the environmental information and are previously defined.

2. The processes in the PS are described by using a top-down procedure that generates PN models [21]. The PN models are structurally and functionally analyzed including simulation techniques for quantitative/qualitative evaluation for different scenarios. The process modeling describes a practical and systematized way of assessing the performance of a sustainable PS by monitoring the indicators defined according to four dimensions of sustainability: environmental, economical, social and technological.

3. The expected KPIs related to sustainability, which are obtained from the PN models are stored at SMS database and used to compare the information collected from the productive plants on-line. It is supposed that the information about the current status of the productive plants is available at the 
MES database; however, there are cases where direct communication from SMS to the supervisory level (lower level) is necessary.

4. The evaluation of the differences among the expected values of KPIs and measured values are reported to superior level (level 4). Although there are cases where some activation commands are previously established (derived from decision of upper level). In this case, a message must be send to MES to update the tasks to be carried out in the PS.

\section{Simulation and Analysis}

The proposed systematization procedure specifies how to execute the evaluation process of sustainability indicators and it could be applied in any type of PSs considering its particularity and complexity. The framework associated with the proposed systematization supports the specification for data acquisition system of equipment, sensors and data network of all information into the industrial infrastructure. The data acquisition systems work continually while the production is operating, this way at any time the responsible staff of the production administration can log in the system and evaluates performance in any network. Then, it can be used Petri editor/Simulator as an analysis tool or any other discrete event tool. The analysis and reports are sent to the upper level system to make a decision.

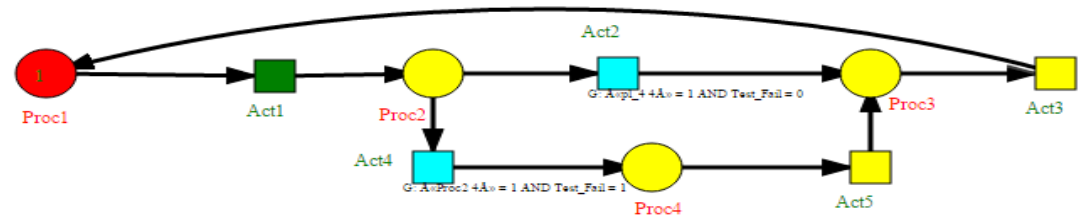

Fig.3. Production representation using Petri Net in IOPT environment.

Figure 3 represents an example of production line where a flow of material goes through PN places indicating three different productive processes: Proc1-> Proc $2->$ Proc3, at approved situation. In each place that an operation is executed it demands energy consumption. If a fail occur in Proc2, the material flow is switched to Proc4 to repair the material and then follows to Proc3. The PN arc between PN transition Act3 and PN place Proc1 assures the sequence of activities. In parallel to production line, there is a measurement system working represented in Figure 4. The elements Sen1_C, Act_R, Sen1_O and Act_W represent a sensor operation that acts when Proc 2 in Figure 3 starts operation, thus the sensor reads the energy consumption and the value read is compared with a pattern value stored in a database. There are three possibilities for the index: normal, regular and high. In all cases after checking the result it is stored in a database. This is executed by tasks (Fig.4): ProcSen1_2, ProcSen1_3 and ProcSen1_3. These results will be used to make decisions at upper level system (level 4). 


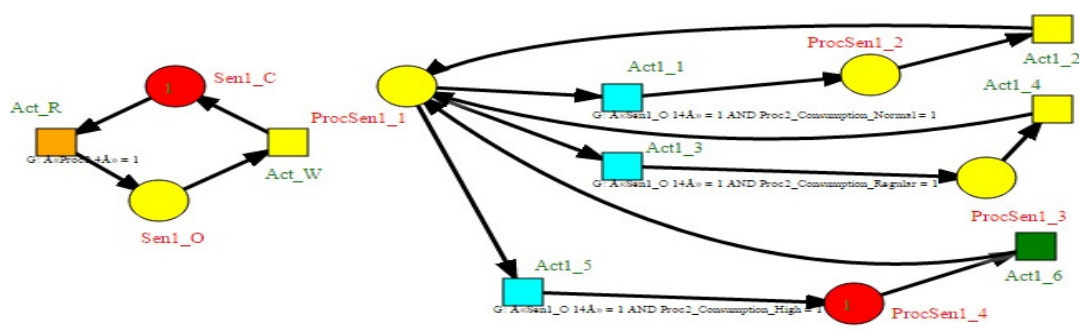

Fig.4. Measure Consumption in Proc2 representation

This measurement structure is applied where the sustainability indexes values are relevant to evaluate the production line.

\section{Conclusions and Further Work}

To evaluate the performance of a PS considering sustainability the ANSI/ISA95 standard structure is reviewed. This paper also defines a set of indicators which can be used to qualify and quantify sustainability in PSs and presents a framework that considers these indicators. The framework adopts the PN technique to consider the sustainable PS design, simulation-based analysis, decision making and classification techniques based on green seal of products. The seal is a register that the framework is in working order. In the adopted approach, the process modeling describes a practical and systematized way of assessing the performance of a sustainable PS by monitoring the indicators defined according to four dimensions of sustainability: environmental, economic, social, and technological. The proposed systematization specifies how to execute the evaluation process of sustainability indicators and it could be applied in any type of PSs considering its particularity and complexity. But the framework needs to be to know its limitations mainly in large systems. Due to limited space in this work, the case shown in section 4 is a small sample of simulation and analysis features that they will be detailed in further works.

Acknowledgements. The authors would like to thank CNPq, CAPES, FAPESP for the financial support.

\section{References}

[1] Senge, P.M., Carstedt, G.; Porter, P.L. (2001). Innovating Our Way to the Next Industrial Revolution. MIT Sloan Management Review; Winter 2001; 42, 2; ABI/INFORM Global pg. 24

[2] Goldstone, J.A. (2002). Efflorescences and Economic Growth in World History: Rethinking the "Rise of the West" and the Industrial Revolution. Journal of World History, v.13, No.2, Fall 2002, pp. 323389.

[3] McDonough, W. and Braungart, M. (1998). The NEXT Industrial Revolution. The Atlantic Monthly, October 1998, V.282, No.4; pp. 82-92.

[4] WCED - World Comission on Environment and Development. Our Commom Future. Oxford and New York: Oxford University Press, 1987. 
84 E. H. Watanabe et al.

[5] ANSI/ISA-95.00.03.2005. ANSI-American National Standart Institute and ISA-The Instrumentation Systems and Automation Society. Enterprise-Control System Integration Part3: Activity Models of Manufacturing Operations Management, 2005.

[6] NIST- National Institute of Standards and Technology. Cloud Computing and Sustainability: The Environmental Benefits of Moving to the Cloud NIST, Cyber-Physical Systems: Situation Analysis of Current Trends, Technologies, and Challenges, National Institute of Standards and Technology (NIST), Columbia, Maryland, 2012,

http://events.energetics.com/NISTCPSWorkshop/pdfs/CPS_Situation_Analysis.pdfi.

[7] Sundmaeker H., Guillemin P., Fries P., Woelffle S., Vision and challenges for realising the internet of things, in: CERP-IoT Cluster of European Research Projects on the Internet of Things, 2010.

[8] Colombo A.W., Karnouskos S., Bangemann T., A system of systems view on collaborative industrial automation, in: IEEE International Conference on Industrial Technology (ICIT 2013), 25-28 Feb, Cape Town, South Africa, 2013.

[9] Veleva, V., Hart, M., Greiner, T., Crumbley, C. Indicators of sustainable production. Jornal of Claaner Production, vol.9, pp.447-452

[10] O'Brien, C. Sustainable production - a new paradigm for a new millennium. International Journal of Production Economics, 1999.

[11] Amrina, E.; Yusof, S. M. KeyPerformance Indicators for Sustainable Manufacturing Evaluation in Automotive Companies. Industrial Engineering and Engineering Management (IEEM), 2011 IEEE International Conference on, Issue Date: 6-9 Dec., 2011

[12] Joung, C.B.; Carrell, J.; Sarkar, P.; Feng, S.C. Categorization of indicators for sustainable manufacturing. Ecological Indicators, 2013

[13] OECD - Organization for Economic Co-operation and Development. Sustainable Development: Critical Issues. OECD Publishing, 2001.

[14] OECD - Organization for Economic Co-operation and Development. Sustainable manufacturing toolkit - Seven steps to environmental excellence, START-UP GUIDE. OECD Publishing, 2011.

[15] Tan, H. X.; Yeoa, Z.; Nga, R.; Tjandraa, T. B.; Song. B. A sustainability indicator framework for Singapore small and medium-sized manufacturing enterprises. The 22nd CIRP conference on Life Cycle Engineering. Procedia CIRP 29 ( 2015 ) 132 - 137

[16] US Department of Commerce, "Sustainable manufacturing initiative", in Proceedings of the $2^{\text {nd }}$ Annual Sustainable Manufacturing Summit Chicago, USA, 2009.

[17] ISO Std.22400-1:2010, Automation systems and integration - Key performance indicators (KPIs) for manufacturing operations management - Part 1: Overview, concepts and terminology, 2010.

[18] ISO Std.22400-2:2014, Automation systems and integration - Key performance indicators (KPIs) for manufacturing operations management - Part 2: Definitions and descriptions of key performance indicators, 2014.

[19] Watanabe, E.H.; Blos, M.F.; da Silva, R.M.; Junqueira, F.; Santos Filho, D.J.; Miyagi, P.E. (2015). A Framework to Evaluate Performance of Disperse Productive System through the Sustainability Performance Indicators. $15^{\text {th }}$ IFAC/IEEE/IFIP/IFORS Symposium Information Control Problems in Manufacturing, Ottawa, Canada.

[20] Watanabe, E.H.; Blos, M.F.; da Silva, R.M.; Junqueira, F.; Santos Filho, D.J.; Miyagi, P. E. (2015) Key Performance Indicators of Disperse Productive System to Evaluate Performance and Sustainability. 23rd ABCM Int. Congress of Mechanical Engineering, Rio de Janeiro, RJ, Brazil.

[21] Miyagi, P. E. Controle Programável - Fundamentos do Controle de Sistemas a Eventos Discretos. (In Portuguese). Editora Edgard Blücher, São Paulo, Brasil, 2001.

[22] Villani, E., Miyagi, P. E., Valette, R. (2007). Modelling and analysis of hybrid supervisory systems: A Petri net approach. London: Springer-Verlag London Limited.

[23] Silva, M. "Half a century after Carl Adam Petri's PhD thesis: A perspective on the field". Annual Reviews in Control, vol. 37, No.2, p. 191-219, 2013.

[24] da Silva, R.M.; Watanabe, E.H.; Blos, M.F.; Junqueira, F.; Santos Filho, D.J.; Miyagi, P.E. (2015) Modeling of Mechanisms for Reconfigurable and Distributed Manufacturing Control System. 6th IFIP WG 5.5/SOCOLNET Doctoral Conference on Computing, Electrical and Industrial Systems, DoCEIS 2015, Costa de Caparica, Portugal, Proceedings. 